\title{
Characteristics of Reliever Inhaler Users and Asthma Control: A Cross-Sectional Multicenter Study in Portuguese Community Pharmacies
}

\author{
Mariana Romão (i) \\ Ana Rita Godinho' \\ Pedro M Teixeira (iD ${ }^{2}$ \\ Zilda Mendes' \\ Filipa Bernardo 3 \\ António Teixeira Rodrigues (D) \\ Jaime Correia de Sousa (iD) 2,4 \\ 'Centre for Health Evaluation \& \\ Research/Infosaude - National \\ Association of Pharmacies (CEFAR/IS- \\ ANF), Lisbon, Portugal; ${ }^{2}$ Life and Health \\ Sciences Research Institute (ICVS)/ \\ 3B's-PT Government Associate \\ Laboratory, University of Minho, Braga, \\ Portugal; ${ }^{3}$ AstraZeneca, Queluz, Lisboa, \\ Portugal; ${ }^{4}$ Horizonte Family Health Unit, \\ ULS Matosinhos, Matosinhos, Portugal
}

Correspondence: Mariana Romão Centre for Health Evaluation \& Research/ Infosaude - National Association of Pharmacies (CEFAR/IS-ANF), Rua

Marechal Saldanha I, Lisboa, 1249-069,

Portugal

Email mariana.romao@anf.pt
Purpose: SABA overuse might indicate poorly managed or uncontrolled asthma and be responsible for poor health outcomes. The aim of this study integrated in new fourth multidesign SABINA+ pillar was to characterize the population using short-acting $\beta_{2}$-agonists for asthma and examine the patterns of its use among community pharmacy customers in Portugal, as well as identify characteristics associated with disease control and explore potential differences between GINA treatment steps.

Patients and Methods: This cross-sectional multicenter study was conducted in Portuguese community pharmacies between 29 May 2018 and 15 August 2018. Participants were adults (age $\geq 18$ years) self-reporting asthma diagnosis recruited in the context of a short-acting $\beta_{2}$-agonist dispense. A two-part questionnaire (pharmacist interview and self-administered) was used to collect information about sociodemographic characteristics, comorbidities, reliever inhaler use, healthcare resource consumption and self-reported disease control (assessed by the Control of Allergic Rhinitis and Asthma Test - CARAT ${ }^{\circledR}$ ). Descriptive statistics was done to characterize the study sample. After categorizing patients according to GINA steps, based on their therapeutic regimen, we performed an exploratory subgroup analysis to evaluate if there were any differences between such groups in terms of the variables collected. A logistic regression was used to identify the potential determinants of overall disease control.

Results: Around $50.8 \%$ of patients were male, and the average age was 52 years old. Half of the patients never smoked, and $51.9 \%$ were employed. More than half of the patients report inhaler overreliance - purchasing more than 1 pack in 3 months $(65.0 \%)$ or using the inhaler on more than 8 days over the previous 4 weeks (50.2\%). Of the total number of patients in the study, $79.1 \%$ had poorly controlled asthma symptoms, and $78.7 \%$ had overall poorly controlled respiratory symptoms. We found statistically significant differences between GINA treatment steps in all sociodemographic characteristics (sex, mean age, education level, employment status); maximum number of SABA uses in $24 \mathrm{~h}$, CARAT score (total an asthma sub-score); history of exacerbations requiring ED visits or treatment with OCS for at least 3 days in the previous 12 months. Logistic regression revealed that patients reporting SABA use in more than 8 days in the previous 4 weeks and patients with at least 1 exacerbation requiring treatment with OCS for at least 3 days in the previous 12 months have greater odds of poor disease control [adjusted OR (95\% CI): $2.6(1.3-5.2)$ and $3.0(1.3-6.6)]$.

Conclusion: Based on the results of this study, it can be inferred that the asthma population using SABA is largely uncontrolled and uses reliever inhalers excessively.

Keywords: chronic disease, short-acting beta-2 adrenergic agonist, overuse, exacerbations, CARAT $^{\circledR}$ 


\section{Introduction}

According to the 2018 Global Asthma Report estimates, asthma affected approximately 339 million people and was accountable for almost $1 \%$ of all-cause disability-adjusted life years (DALY) in that year, globally. ${ }^{1}$

In Portugal, the estimated life-long prevalence of the disease is $10.5 \%,{ }^{2-4}$ posing a serious public health problem with considerable impact on quality of life.

Short-acting $\beta 2$-agonists (SABA) are usually prescribed to manage episodes of asthma exacerbation. However, these medications are so successful in relieving symptoms that they are often over relied on to the detriment of the controller treatment. ${ }^{5}$ SABA overuse might indicate poorly managed or uncontrolled asthma and be responsible for a progressive worsening of the disease. Considering that the use of more than one unit of 200 doses of SABA per month is associated with a higher risk of exacerbation and death, this indicator should deserve special attention from health professionals. ${ }^{6}$ Overall, the excessive use of SABA may increase the risk for cardiovascular problems, depression, severe exacerbations, and even death. $^{7-9}$

At the time of the present study, there was no information available about SABA utilization patterns in Portugal as well as its association with asthma control. It is important to know the extent of SABA overuse in the Portuguese asthma population so that health professionals can define strategies to address this public health issue.

The aim of this SABINA+ study was to characterize the population using a short-acting beta-2 agonist for asthma, among community pharmacy customers in Portugal. In detail, the study sought to describe the sociodemographic, clinical and health characteristics, therapeutic regimen, and disease control of the study sample. Additionally, the present study tried to identify the relationship between reliever inhaler overuse and disease control, and to explore the patients' features associated with disease control.

\section{Materials and Methods Study Design and Data Collection}

This observational, cross-sectional, multicenter study of patients with asthma who acquired a SABA inhaler belongs to the new fourth multi-design SABINA+ pillar. Details of the original SABINA program were published previously. $^{10}$
This study was conducted in Portuguese community pharmacies affiliated with the National Association of Pharmacies (ANF) (95\% of all pharmacies in Portugal). A poll of 2437 pharmacies using the Sifarma ${ }^{\circledR}$ software ( $83.4 \%$ of the total pharmacies in Portugal) were invited to participate. Among these, 432 accepted the invitation, and 168 recruited patients for the study $(6.9 \%$ of the invited sample). Pharmacies willing to participate expressed their consent through an online form, after being informed about the study procedures.

The participating pharmacies were trained on the study protocol and received a study binder with all the materials needed to implement the study according to study procedures.

When dispensing a SABA inhaler, a pop-up alert was generated by the pharmacy software, to remind the pharmacist to verify patient's compliance with the eligibility criteria: (1) Being the SABA user, (2) aged $\geq 18$ years, (3) with a self-reported diagnosis of asthma, (4) with no cognitive impairment and (5) providing informed consent to participate in the study. The pop-up alert also aimed to decrease participant self-selection.

The self-reported asthma diagnosis was complemented by a set of questions on age at the time of diagnosis, early childhood or teenage symptom onset, history of allergies, spontaneous symptom improvement or immediate response to bronchodilator treatment, and drug regimen (coexistence of SABA, leukotriene receptor antagonists or inhaled corticosteroids in association with either shortor long-acting $\beta 2$-agonists).

Patients were excluded when the pharmacy customer was not the user of the inhaler. If a patient refused to participate, pharmacists were asked to complete a refusal form with the customer's sociodemographic information and reason for refusal.

Data was collected through a completely anonymous two-part questionnaire. The first part consisted of a pharmacist interview collecting data on the therapeutic regimen and the prescribed SABA inhaler dosage and posology. The second part, a self-administered questionnaire, collected information about the socio-demographic characteristics, comorbidities, patterns of SABA inhaler use, history of asthma exacerbations, asthma-related healthcare utilization and disease control. A validated patient-reported outcome measure - the Control of Allergic Rhinitis and Asthma Test $\left(\right.$ CARAT $\left.^{\circledR}\right)$ was used to assess disease control. ${ }^{11}$ 


\section{Sample Size}

The study was powered to estimate proportions with an absolute error of $5 \%$ and a $95 \%$ confidence level, resulting in a minimum sample size of 385 patients. Based on average monthly SABA sell-out in the pharmacies and assuming a minimum of 300 participating pharmacies and $50 \%$ refusal rate we estimated that a period of approximately 11 weeks would be enough to reach the needed sample.

\section{SABA Inhaler Overuse and Disease Control}

Asthma control was assessed by the Control of Allergic Rhinitis and Asthma Test $\left(\right.$ CARAT $\left.^{\circledR}\right){ }^{11}$ This test consists of 10 questions, each scored on a 4-point Likert scale and divided into two domains: allergic rhinitis (question 1-4) and asthma (question $5-10$ ). Overall disease control is defined as a CARAT score of $\geq 24$ points, while asthma control is defined as a CARAT Asthma sub score of $\geq 16$ points.

SABA overuse was assessed through 4 different indicators:

- Number of days with SABA use in the previous 4 weeks (overuse defined as using more than 8 days ${ }^{12}$ );

- Average number of SABA uses per day in the previous 4 weeks (overuse defined as 3 or more uses ${ }^{12}$ );

- Maximum number of SABA uses in a 24-hour period, ever (overuse defined as more than 4 uses).

- Number of canisters purchased in the previous 3 months (given the population habits of medication purchase, the research team decided to consider a shorter recall period).

\section{Therapeutic Regimen}

The therapeutic regimen was classified according to the GINA's 2019 update. ${ }^{13}$ All the medicines used for asthma treatment as self-reported by patients in the pharmacist interview were entered in the database. Participants were classified in terms of their therapeutic regimen to one of the five steps of asthma treatment according to GINA 2019 recommendations. As it was impossible to distinguish treatment for steps 3 and 4 (because the questionnaire did not collect the dose and posology of asthma medications apart from the SABA inhaler), these were treated together as a single category. When patients reported using drugs that were compatible with both asthma and COPD treatment, they were allocated to the therapeutic regimen category of "Probable ACO/COPD". When the combination of reported medicines indicated use of treatment for an exacerbation (eg, oral corticosteroids) they were allocated to the category of "Probable exacerbation". Due to possible coding errors, it was not possible to classify 14 patients (total of patients characterized $=374$ ).

\section{Statistical Analysis}

Patients who did not accept to participate were characterized and compared with those participating to evaluate if there were any differences caused by sampling bias. The distribution of pharmacies that recruited patients was compared with the geographic distribution of community pharmacies using a Chi-square test for adjustment.

A descriptive analysis of the collected variables was performed. Categorical variables were summarized by absolute and relative frequencies. Continuous variables were summarized using central tendency and dispersion measurements. All the percentages were calculated excluding missing values. Independent sample group differences were analyzed using the Chi-square statistic. Stepwise logistic regression analysis was performed to identify and evaluate the association between different characteristics (sociodemographic, therapeutic regimen, health resource use, SABA overreliance, comorbidities) and the overall disease control. Data analysis was performed with SAS ${ }^{\circledR}$ Enterprise Guide ${ }^{\circledR} 4.1$ and IBM SPSS Statistics V26.0 using a p-value cut-off of 0.05 .

\section{Results}

Between 29 May 2018 and 15 August 2018, a total of 168 pharmacies participating in the study invited 678 patients to the study. Of these, a total of 405 patients accepted to participate (patient participation rate $=59.7 \%$ ). Of all the questionnaires collected in the pharmacies, 17 were excluded from the analysis due to non-compliance with the inclusion criteria or due to inconsistent filling. The final sample consisted of 388 questionnaires collected by 143 pharmacies (Figure 1).

Pharmacies collecting questionnaires included in the analysis were representative of the geographic distribution of the Portuguese community pharmacies' population ( $\mathrm{p}>$ 0.05). When comparing the characteristics of the study participants with those who did not agree to participate, no statistically significant differences were found regarding sex and age ( $>0.05)$. The main reason for refusal (69.5\%) was lack of time to participate. 


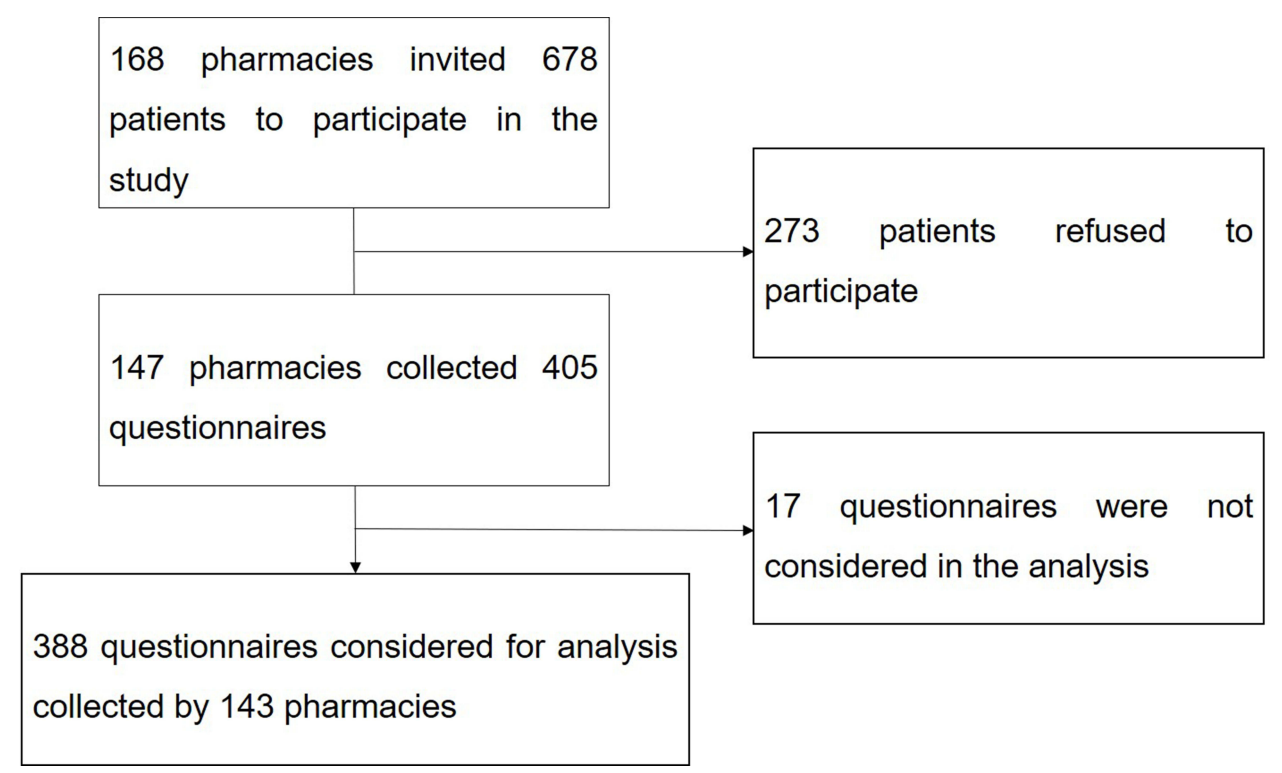

Figure I Study participation flowchart.

\section{Participants' Characteristics}

The characteristics of the study sample are shown in Table 1. The mean (SD) age was 51.8 years (17.8) and $28.3 \%$ of the patients were over 65 years of age. Overall, $50.8 \%$ were male and $48.1 \%$ were not employed. Half the patients did not complete the mandatory education (12th grade in Portugal), and, of these, 18 patients reported they had never completed any education level (4.9\% of total). Participants included 50.3\% who had never smoked, and $60.7 \%$ who were overweight (BMI over $25 \mathrm{~kg} / \mathrm{m} 2$ ).

Of the patients who reported having comorbidities, the majority indicated they had up to 2 comorbidities (70\%). The most frequently mentioned comorbidities in patients with only 1 more chronic disease besides asthma were hypertension (32.7\%), anxiety (24.0\%) and depression (17.5\%). In patients with 2 comorbidities, the most common comorbidities were hypertension and diabetes $(22.7 \%)$.

Family medicine was the specialty most frequently mentioned by patients $(56.4 \%)$ who had asthma-related physician appointments in the previous 12 months. Of these, $57.1 \%$ had asthma-related appointments with a family doctor and $42.9 \%$ also had appointments with other specialists. Moreover, $48.1 \%$ of the patients mentioned that their first reliever inhaler was prescribed by a family doctor.

\section{SABA Inhaler Overuse and Asthma Control}

Patients self-reported the prescribed SABA posology. The mean (SD) number of actuations per use was 2 (1), and the mean (SD) of the maximum number of SABA uses in a day was 3 (2).

The mean (SD) number of canisters purchased in the previous 3 months was 3 (3), and approximately $65.0 \%$ of the patients purchased 2 or more canisters of SABA during that period (Table 2). Regarding the number of days with inhaler use in the previous 4 weeks, the mean (SD) was 14.0 days (10.6), and around half of the patients used the inhaler more than 8 days $(50.2 \%)$. The mean (SD) daily SABA use was 2.1 (1.8) and $22.5 \%$ of the patients used the inhaler 3 or more times per day. In a 24-hour period, the mean (SD) maximum number of SABA uses was 4.0 (2.9) but $25.4 \%$ of the patients exceeded 4 uses of the inhaler in a 24 -hour period.

Considering overuse as purchasing 2 or more SABA canisters in the previous 3 months, we found that over users were older, patients with smoking history, retired or unemployed, with lower education and patients who reported the remaining SABA utilization metrics related to overuse (statistically significant differences, $\mathrm{p}<0.05$ ). A higher proportion of patients with history of exacerbation requiring hospital admission and uncontrolled asthma were found among over users.

According to the CARAT $^{\circledR}$ total score, $78.7 \%$ of the participants had uncontrolled disease. The results of the CARAT ${ }^{\circledR}$ Asthma sub score revealed that $79.1 \%$ of the patients had uncontrolled asthma (Figure 2). 
Table I Demographic and Characteristics of Patients Purchasing a SABA Inhaler

\begin{tabular}{|c|c|}
\hline Characteristic & $\begin{array}{c}\text { Mean (SD) or } \\
n(\%)\end{array}$ \\
\hline Total & $388(100)$ \\
\hline Age (years) & $51.8(17.8)$ \\
\hline \multicolumn{2}{|l|}{ Age group (years) } \\
\hline $18-25$ & $23(6, I)$ \\
\hline $26-35$ & $38(10,1)$ \\
\hline $36-45$ & $88(23,3)$ \\
\hline $46-55$ & $62(16,4)$ \\
\hline $56-65$ & $60(15,9)$ \\
\hline $66-75$ & $60(15,9)$ \\
\hline Over 75 & $47(12,4)$ \\
\hline Missing & 10 \\
\hline \multicolumn{2}{|l|}{ Sex } \\
\hline Female & $190(49.2)$ \\
\hline Male & $196(50.8)$ \\
\hline Missing & 2 \\
\hline \multicolumn{2}{|l|}{ BMI $\left(\mathrm{kg} / \mathrm{m}^{2}\right)$} \\
\hline Underweight $(<18.5)$ & $13(0.8)$ \\
\hline Normal (I8.5-24.9) & $144(38.5)$ \\
\hline Overweight (25-29.9) & $133(35.6)$ \\
\hline Obese class I (30-34.9) & $69(18.4)$ \\
\hline Obese class II (35-39.9) & $18(4.8)$ \\
\hline Obese class III $(\geq 40)$ & $7(1.9)$ \\
\hline Missing & 14 \\
\hline \multicolumn{2}{|l|}{ Smoking history } \\
\hline Never & $177(50.3)$ \\
\hline Ex-smoker & $87(24.7)$ \\
\hline Current smoker & $88(25.0)$ \\
\hline Missing & 36 \\
\hline \multicolumn{2}{|l|}{$\begin{array}{l}\text { Education level (Portuguese education } \\
\text { system) }^{a}\end{array}$} \\
\hline No education & $18(4.9)$ \\
\hline Ist cycle (Basic Ed.) & $96(26.0)$ \\
\hline 2nd cycle (Basic Ed.) & $25(6.8)$ \\
\hline 3rd cycle (Basic Ed.) & $45(12.2)$ \\
\hline Secondary education & $96(26.0)$ \\
\hline Higher education & $89(24.1)$ \\
\hline Missing & 19 \\
\hline \multicolumn{2}{|l|}{ Employment status } \\
\hline Employed & $194(51.9)$ \\
\hline Unemployed & $37(9.9)$ \\
\hline Retired & $122(32.6)$ \\
\hline Other & $21(5.6)$ \\
\hline Missing & 14 \\
\hline
\end{tabular}

(Continued)
Table I (Continued).

\begin{tabular}{|l|c|}
\hline Characteristic & $\begin{array}{c}\text { Mean (SD) or } \\
\mathbf{n}(\%)\end{array}$ \\
\hline Comorbidities & $104(42.8)$ \\
I comorbidity & $66(27.2)$ \\
2 comorbidities & $73(30.0)$ \\
3 or more comorbidities & 145 \\
Missing & \\
\hline Medical specialty of asthma-related doctor & \\
appointments & \\
Family medicine & $219(56.4)$ \\
Pulmonology & $148(38.1)$ \\
Allergology & $54(13.9)$ \\
Internal medicine & $20(5.2)$ \\
Other & $13(3.4)$ \\
\hline GINA step & \\
Step I & $128(33.0)$ \\
Step 2 & $49(12.6)$ \\
Step 3 e 4 & $86(22.2)$ \\
Step 5 & $41(10.6)$ \\
Probable ACO/COPD & $54(13.9)$ \\
Probable exacerbation & $16(4.1)$ \\
Non classified & $14(3.6)$ \\
\hline
\end{tabular}

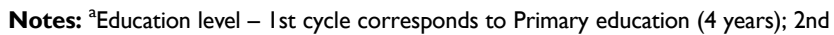
cycle corresponds to Primary education ( 2 years); 3 rd cycle corresponds to Secondary general education (3 years); Secondary education corresponds to Secondary general education ( 3 years); Higher education corresponds to Tertiary education (full-time, between 3 and 7 years). ${ }^{b}$ Patients could report more than one specialty with asthmarelated doctor appointments. 'According to the GINA's 2019 update.

Abbreviations: ACO/COPD, Asthma-COPD overlap/Chronic obstructive pulmonary disease; $\mathrm{BMI}$, body mass index; SD, standard deviation.

\section{Subgroup Analysis by Asthma Therapeutic Regimen (GINA)}

Based on the therapy regimen, the majority of patients are classified as step 1 (33.0\%), followed by step 3 and 4 (22.2\%) and step $2(12.6 \%)$. Of the patients, $13.9 \%$ were classified as probable ACO/COPD (Table 3). To limit the extension of the table, we decided to present in Table 3 only the variables where we found statistically significant differences between GINA steps. The complete subgroup analysis can be found in Supplementary Material 1.

We found statistically significant differences between GINA groups for age (mean), sex, education level (Portuguese education system) and employment status. It seems that age increased from step 1 to step 5 of GINA classification. Patients belonging to the "Probable exacerbation" group have a mean age similar to those on steps 1 
Table 2 SABA Overuse

\begin{tabular}{|c|c|}
\hline Characteristic & n (\%) \\
\hline Total & $388(100)$ \\
\hline $\begin{array}{l}\text { Number of canisters purchased in the previous } 3 \\
\text { months }\end{array}$ & \\
\hline I package & $120(35.0)$ \\
\hline$\geq 2$ packages & $223(65.0)$ \\
\hline Missing & 45 \\
\hline $\begin{array}{l}\text { Number of days with SABA use in the previous } 4 \\
\text { weeks }\end{array}$ & \\
\hline$\leq 8$ days & $150(49.8)$ \\
\hline$>8$ days & $|5|(50.2)$ \\
\hline Missing & 87 \\
\hline $\begin{array}{l}\text { Average number of SABA uses per day in the } \\
\text { previous } 4 \text { weeks }\end{array}$ & \\
\hline$\leq 2$ uses & $252(77.5)$ \\
\hline$>2$ uses & $73(22.5)$ \\
\hline Missing & 63 \\
\hline $\begin{array}{l}\text { Maximum number of SABA uses in a 24-hour } \\
\text { period }\end{array}$ & \\
\hline$\leq 4$ uses & $223(74.6)$ \\
\hline$>4$ uses & $76(25.4)$ \\
\hline Missing & 89 \\
\hline $\begin{array}{l}\text { History of exacerbations requiring an ED visit in } \\
\text { the previous } 12 \text { months }\end{array}$ & \\
\hline No & $207(60.3)$ \\
\hline Yes & $136(39.7)$ \\
\hline Missing & 45 \\
\hline $\begin{array}{l}\text { History of exacerbations requiring treatment } \\
\text { with OCS for at least } 3 \text { days in the previous } 12 \\
\text { months }\end{array}$ & \\
\hline No & $207(64.1)$ \\
\hline Yes & $116(35.9)$ \\
\hline Missing & 65 \\
\hline $\begin{array}{l}\text { History of exacerbations requiring hospital } \\
\text { admission for at least one night in the previous } \\
\text { I } 2 \text { months }\end{array}$ & \\
\hline No & 304 (87.6) \\
\hline Yes & $43(12.4)$ \\
\hline Missing & $4 I$ \\
\hline
\end{tabular}

Note: P-values calculated excluding the 14 patients not classified by the algorithm. Abbreviations: CARAT ${ }^{\circledR}$, Control of Allergic Rhinitis and Asthma Test; ED, emergency department; OCS, oral corticosteroid; SABA Short-acting $\beta_{2}$-agonists.

and 2. Patients with probable ACO/COPD register the highest mean age. Female sex was more frequent in step 1, 2 and Probable ACO/COPD patients. In the Probable $\mathrm{ACO} / \mathrm{COPD}$, we also found a higher proportion of patients with the lowest levels of education $(59.6 \%$ with 1 st cycle or even no education). On the other hand, step 2 has the highest proportion of highly educated participants (40.8\%). Regarding employment status, there is a majority of employed patients in all subgroups, except in the probable ACO/COPD subgroup, where there is a predominant proportion of retired participants (53.8\%).

Analyzing by asthma therapeutic regimen (GINA), we found statistically significative differences for the maximum number of SABA uses in a 24-hour period, and CARAT $^{\circledR}$ scores (global and asthma sub score). Patients in steps 1 to 5 and probable ACO/COPD had higher percentage of up to 4 uses as the maximum SABA use in a 24-hour period, while the probable exacerbation group registered a higher proportion of patients using the SABA inhaler more than 4 times in the same period.

The subgroup analysis revealed that step 1 has the highest proportion of patients with controlled disease, considering both the total and the asthma sub score.

Statistically significant differences were found for Pulmonology asthma-related appointments. Patients on GINA's Step 5 treatment and Probable ACO/COPD visited a Pulmonology specialist more often than the others.

Patients self-reported the occurrence of exacerbations in the previous 12 months: $35.9 \%$ led to a visit to the emergency department (ED), 39.7\% required treatment with oral corticosteroids (OCS) for at least 3 days and $12.4 \%$ experienced resulted in hospitalization for at least 1 night.

The proportion of patients with no visits to the ED due to asthma in the previous 12 months decreased as the GINA treatment step increased. In step 1, 27.9\% of the participants registered at least one visit to the ED (vs $72.1 \%$ who did not register any visit). As the GINA treatment step increases, these differences got narrower, until there was a higher proportion of patients with history of exacerbation requiring ED care in step 5. Almost half of the probable $\mathrm{ACO} / \mathrm{COPD}$ group had at least one exacerbation requiring a visit to the $\mathrm{ED}$, whereas the probable exacerbation subgroup has a considerably higher proportion of these patients.

In steps 1 and 2, similarly to the probable ACO/COPD group, there is a lower proportion of patients with history of at least one exacerbation requiring the prescription of an oral corticosteroid. This proportion significantly increases in step 3 and 4 and step 5, where exactly half of the patients self-reported the prescription of OCS in the sequence of an asthma exacerbation in the previous 12 months. The probable exacerbation group has 
A

CARAT $^{\circledR}$ score - overall disease control

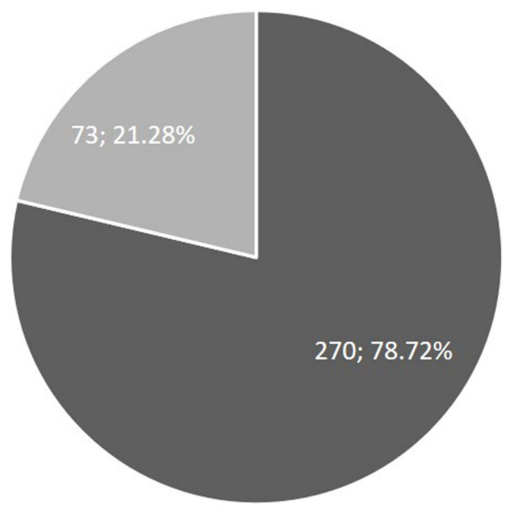

- Uncontrolled disease $\quad$ Controlled diseased

Figure 2 Disease $(\mathbf{A})$ and asthma symptom control (B), assessed by CARAT $^{\circledR}$.

a significantly higher proportion of patients who had at least one of these episodes.

\section{Patients' Features Associated with Disease Control}

A logistic regression analysis was implemented on 279 patients. The remaining 105 patients were excluded from the analysis due to having at least one missing variable. All variables had less than $10 \%$ missing values, except for "number of canisters purchased in the previous 3 months" (Nonrespondents, $\mathrm{NR}=11.6 \%$ ), "number of days with SABA use in the previous 4 weeks" (NR=22.4\%), "number of SABA uses per day" (NR=16.2\%), "Maximum number of SABA uses in a 24-hour period" $(\mathrm{NR}=19.3 \%)$, "CARAT ${ }^{\circledR}$ score" $(\mathrm{NR}=11.6 \%)$, "number of exacerbations requiring an ED visit" ( $\mathrm{NR}=11.6 \%)$, "number of exacerbations requiring an ED with OCS prescription for at least 3 days" ( $\mathrm{NR}=16.8 \%)$ and "number of exacerbations requiring a hospital admission for at least one night" ( $\mathrm{NR}=10.6 \%)$. This subgroup did not differ from the 374 regarding the therapeutic regimen classification $(p$ $=0.787)$. Two variables significantly influenced the overall disease control: Number of days with use of SABA inhaler in the previous 4 weeks and the Number of exacerbations requiring an ED visit and treatment with oral corticosteroids for at least 3 days. The unadjusted and adjusted ORs and corresponding 95\% CI are summarized in Table 4.

For patients who use the SABA inhaler more than 8 days in a period of 4 weeks, the odds of uncontrolled
B

CARAT $^{\circledR}$ asthma sub-score - asthma symptom control

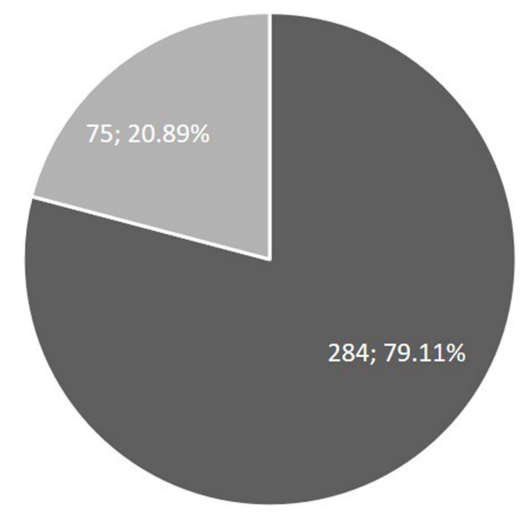

- Uncontrolled Asthma $\quad$ - Controlled Asthma

overall disease are 2.6 times greater than the odds for patients who use the inhaler up to 8 days (adjusted OR 2.6, 95\% CI 1.3-5.2).

For patients who, in a period of 12 months, had at least one exacerbation that required an emergency department visit with oral corticosteroids prescription for at least 3 days, the odds of uncontrolled overall disease are 2.9 times greater than the odds for patients who did not have any exacerbations (adjusted OR 3.0, 95\% CI 1.3-6.6).

\section{Discussion}

This SABINA+ study demonstrated a frequent and excessive use of SABA as well as a high rate of uncontrolled asthma among community pharmacy customers using SABA in Portugal. Despite differences in study design, these findings are similar to those of other SABINA studies conducted in Europe ${ }^{14-16}$ and should be very concerning for health authorities, health professionals, and asthma patients. According to the literature, the use of SABA can be indicative not only of the level of asthma control, ${ }^{17}$ but also of the occurrence of exacerbations, ${ }^{14-16}$ of the use of healthcare resources, ${ }^{7,18}$ and even the physical and mental impairment of the patient. ${ }^{9}$

\section{Comparison with National Reality}

The Portuguese National Asthma Survey (INAsma) studied the asthma prevalence in Portugal (INPA) and characterized the asthma population nationwide, in terms of sociodemographic and clinical characteristics such as sex, age, BMI, smoking status, disease control (INCA). ${ }^{2}$ The 
Table 3 Subgroup Analysis According to GINA Therapeutic Steps (Statistically Significant Differences)

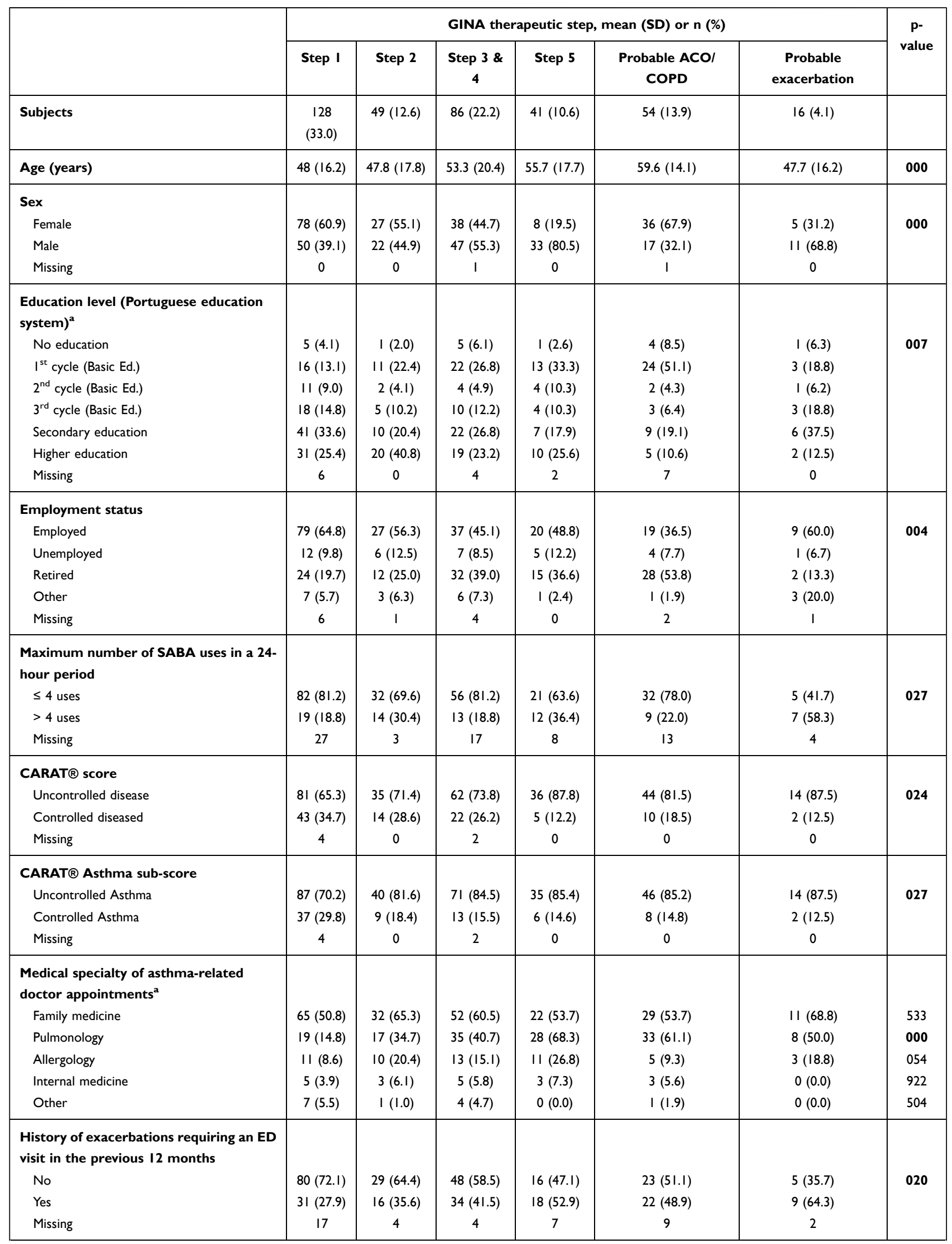

(Continued) 
Table 3 (Continued).

\begin{tabular}{|c|c|c|c|c|c|c|c|}
\hline & \multicolumn{6}{|c|}{ GINA therapeutic step, mean (SD) or n (\%) } & \multirow{2}{*}{$\begin{array}{c}\mathrm{p}- \\
\text { value }\end{array}$} \\
\hline & Step I & Step 2 & $\begin{array}{c}\text { Step } 3 \& \\
4\end{array}$ & Step 5 & $\begin{array}{c}\text { Probable ACOI } \\
\text { COPD }\end{array}$ & $\begin{array}{c}\text { Probable } \\
\text { exacerbation }\end{array}$ & \\
\hline \multicolumn{8}{|c|}{$\begin{array}{l}\text { History of exacerbations requiring } \\
\text { treatment with OCS for at least } 3 \text { days in } \\
\text { the previous } 12 \text { months }\end{array}$} \\
\hline No & $85(81.7)$ & $27(65.9)$ & $38(50.0)$ & $18(50.0)$ & $29(69.0)$ & $4(33.3)$ & 000 \\
\hline Yes & $19(18.3)$ & $14(34.1)$ & $38(50.0)$ & $18(50.0)$ & $13(31.0)$ & $8(66.7)$ & \\
\hline Missing & 24 & 8 & 10 & 5 & 12 & 4 & \\
\hline
\end{tabular}

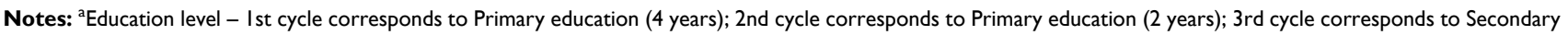
general education ( 3 years); Secondary education corresponds to Secondary general education ( 3 years); Higher education corresponds to Tertiary education (full-time, between 3 and 7 years). P-values calculated excluding the 14 patients not classified by the algorithm. P-values in bold show statistically significant differences ( $P<0.05)$. Abbreviations: ACO/COPD, Asthma-COPD overlap/Chronic obstructive pulmonary disease; BMI, body mass index; SD, standard deviation; CARAT ${ }^{\circledR}$, Control of Allergic Rhinitis and Asthma Test; ED, emergency department; OCS, oral corticosteroid; SABA, Short-acting $\beta_{2}$-agonists.

SABINA Portugal study has a higher proportion of patients in the higher BMI classes when compared to the INCA study: $60.7 \%$ vs $46.9 \%$ of overweight patients (BMI $>25 \mathrm{~kg} / \mathrm{m} 2$ ) and $25.1 \%$ vs $18.4 \%$ of patients with obesity (BMI $>30 \mathrm{~kg} / \mathrm{m} 2)$. This may explain some of the differences found in the level of asthma control of this sample, which was substantially lower than that of the INCA study.

Table 4 Odds Ratios for Overall Disease Control (Unadjusted and Adjusted) and Respective 95\% Confidence Intervals

\begin{tabular}{|l|c|c|}
\hline Variable & $\begin{array}{c}\text { Unadjusted } \\
\text { OR (95\% CI) }\end{array}$ & $\begin{array}{c}\text { Adjusted* } \\
\text { OR (95\% } \\
\text { Cl) }\end{array}$ \\
\hline $\begin{array}{l}\text { Number of days with SABA use in } \\
\text { the previous 4 weeks } \\
\leq 8 \text { days } \\
>8 \text { days }\end{array}$ & - & - \\
\hline $\begin{array}{l}\text { History of exacerbations requiring } \\
\text { OCS prescription for at least } 3 \\
\text { days, in the last I2 months } \\
\text { No } \\
\text { Yes }\end{array}$ & $2.9(1.5-5.6)$ & $2.6(1.3-5.2)$ \\
\hline
\end{tabular}

Notes: *Adjusted for sociodemographic variables, BMI, smoking history, therapeu tic regimen, comorbidities, number of packages purchased in the last 3 months, average number of SABA uses per day, maximum number of SABA uses in a $24-$ hour period, medical specialty of asthma-related doctors' appointments, history of exacerbation ED visit in the previous 12 months or requiring hospital admission for at least one night in the previous 12 months.

Abbreviations: OCS, oral corticosteroid; SABA, Short-acting $\beta 2$-agonists.
While in this sample approximately $50 \%$ of the individuals were smokers or ex-smokers, the INCA study reveals a lower smoking prevalence $(23.2 \%$ of smokers or ex-smokers), ${ }^{19}$ which may also help explaining the values obtained for disease control.

The patients participating in this study reported a higher education level, around $50.1 \%$ had a secondary education level or higher compared to $34 \%$ in the INCA study. It is important to bear in mind that the national survey included individuals under the age of 18 , which may explain these differences.

Regarding the use of health resources due to asthma exacerbations, $39.6 \%$ of the patients reported at least one visit to an emergency service (compared to $23 \%$ of the national population), and $12.4 \%$ were hospitalized at least for one night (vs $3 \%$ of national population). ${ }^{2}$

The main differences between our study and the INCA reported above may be a result of the selection criteria of the participants for the present study. Only those individuals who went to the pharmacy to purchase a SABA inhaler were invited to participate, which may have lowered the representativeness of patients with controlled asthma in this study, since those individuals are less likely to resort to a reliever inhaler.

\section{Overuse}

Several measures of SABA use were explored to identify and characterize the patterns of the drug use by the population. 
Around half the participants (50.2\%) reported using the reliever in more than 8 days over the previous 4 weeks. According to the Directorate-General of Health of Portugal (DGS) Standard No. 006/2018, requiring the reliever inhaler more than twice a week in the previous 4 weeks, is a factor used in the definition of poor asthma control. Additionally, the presence of daytime symptoms, night waking or any activity limitation due to asthma, requires a review of the diagnosis, the inhalation technique and the patient's therapeutic plan. ${ }^{20}$ Therefore, the number of days with reliever use in the previous 4 weeks is a potential predictor for poor disease control. Moreover, $26.9 \%$ of the patients in the study reported using the inhaler daily, which means that some patients may be using the SABA inhaler as controller treatment. This is consistent with findings from the study of Gerald et al in which overuse was most attributable to frequent use on symptom-free days, ie, patients used the reliever inhaler as a daily controller treatment, which not only has not proven to be beneficial as may induce a paradoxical pharmacological reaction. ${ }^{9}$

About $22.5 \%$ of the patients reported using the inhaler three or more times a day. Since the most frequent prescription was 2 actuations per use, we can infer that this percentage of the sample used, on average, 6 or more SABA actuations per day. According to Patel et al, a patient using, on average, 6 SABA actuations per day has twice the odds of having a severe asthma exacerbation in the following 6 months, when compared to a patient with no reliever use in the previous two weeks. ${ }^{19}$

The results of the present study reveal that a quarter of the respondents (25.4\%) have used the inhaler more than 4 times in a 24-hour period. According to the literature, the maximum number of uses in a single day, even in patients who do not frequently use the inhaler excessively, is a predictor of poor disease control in the future. ${ }^{8}$

Assuming as a reference the maximum daily dose of 8 doses and the DGS Standard 006/2018 ${ }^{20}$ of 2 days per week of inhaler use, ie, 192 doses in 3 months, we can infer that patients who have purchased more than one canister (200 doses) in the previous 3 months are overusing it.

Thus, at least $65.0 \%$ of the patients in the present study were overusing the SABA inhaler. It should also be noted that $21.9 \%$ purchased 3 canisters in the previous 3 months (equivalent to one pack per month) and $17.5 \%$ had purchased more than 3 canisters. A study conducted in the United States revealed that $15 \%$ of patients with asthma used more than 1 canister of SABA per month. ${ }^{21}$
Considering that the use of more than 1 canister (200 doses) of SABA per month is associated with the risk of exacerbations and death, ${ }^{6}$ health professionals should pay special attention to this indicator. In these cases, the Royal College of Physicians recommends making an urgent medical appointment to review the patient's condition. ${ }^{22}$

Identifying the factors associated with the excessive use of SABA proves to be of major importance in assessing the future risk of asthma exacerbations.

\section{Measures of Asthma Control}

The CARAT $^{\circledR 11}$ is recommended by the DGS to follow-up asthma patients and was used in this study to evaluate disease control. This type of patient-related outcome measure is very important for clinical practice. ${ }^{23}$

According to the results of this study, $78.7 \%$ of the patients had poor overall disease control and $79.1 \%$ had poorly controlled asthma. The findings regarding asthma control are particularly serious considering the clear association between this indicator and the risk of future exacerbations, not only from a clinical point of view but also due to its serious economic consequences. ${ }^{19}$ In a UK study, the cost per person with poorly controlled asthma was double, compared to well-controlled individuals (£6592 vs $£ 3220$ ). ${ }^{24}$ In the US, the 20 -year projected economic burden associated with uncontrolled asthma is estimated to be $\$ 963.5$ billion, which highlights the need to address this global concern. ${ }^{25}$

The Portuguese National Survey on Asthma Control, INCA (INAsma), published in 2015, revealed that 56.9\% of the Portuguese asthma population was controlled. ${ }^{26}$ Although a direct comparison of the results from the SABINA Portugal and the INCA study is not possible because the populations under study are different, one indicator from the national survey, which states that most uncontrolled patients have a misperception about their disease control, ${ }^{26}$ makes the asthma control results obtained in our study even more alarming. Furthermore, the number of days with use of SABA inhaler in the previous 4 weeks and the number of exacerbations requiring an ED visit and treatment with oral corticosteroids for at least 3 days seem to be significantly associated with poor overall disease control.

\section{Strengths and Limitations}

This study uses real-world data to describe the patterns of SABA utilization among asthma patients treated with a SABA inhaler and to estimate said population's level of 
asthma control. By collecting data through pharmacies, the study ensures both the representativeness of the Portuguese population and the quality of the data related to the therapeutic regimen (comparing to self-reported data). This provides a better picture of the medicines' utilization patterns in the usual practice in the Portuguese context.

However, this study is not without limitations, and the results should be addressed carefully, taking into consideration the methods used for data collection and potential biases. The generalization of this study's findings and the comparison with other studies should be done with caution, since the study sample may not be comparable with the population of similar studies.

There were no significant differences between the regional distribution of pharmacies participating in the study and the pharmacies at a national level, and between the characteristics of patients under study and the patients that refused to participate, which reduces the possibility of selection bias.

One of the most interesting aspects of the study is the collection of real-world data from patients with asthma who use SABAs. Even so, part of the data collected was self-reported and some questions required a 12 months' recollection period, consequently there is a possibility for response and recall bias. The reliability of patient-reported history of asthma or age at diagnosis is high, ${ }^{27}$ as well as the validity of self-reported medication use. ${ }^{28}$ However, the long recall period might have affected the reporting of past events, particularly the mild ones, as well as recent history events of SABA utilization might have increased the long-term estimation.

Although to a small degree, the total sample may have included SABA users other than asthmatic patients. However, it is not possible to estimate the impact of this aspect on the overall results.

Despite the several attempts to minimize bias in the study design and analysis, there may still exist some residual confounding. The small sample size of some of the subgroups examined also limits the interpretation of the study results.

\section{Conclusions}

This study reveals an overuse of SABA among patients with self-reported diagnosis of asthma visiting Portuguese pharmacies to purchase a SABA inhaler. The study also indicates that, among these patients, asthma is largely uncontrolled. Using the SABA inhaler more than 8 days in the previous 4 weeks and having history of exacerbation treated with an oral corticosteroid was associated to poor asthma control.

Improving these indicators and, thereby, reducing the expected clinical and economic costs with asthma patients is of most importance. The results of this study can support the decision makers and the different health professionals in the development of strategies to improve asthma management in Portugal.

\section{Data Sharing Statement}

The data that support the findings of this study are available from the corresponding author upon reasonable request.

\section{Ethics Approval and Informed Consent}

This study was conducted in accordance with the Declaration of Helsinki and approved by the Institute of Bioethics of the Catholic University of Porto (ERS: 04A/2018). All participants provided signed informed consent.

\section{Consent for Publication}

All authors reviewed the manuscript and consent with the publication of its content, including images and text.

\section{Acknowledgments}

The authors are grateful to all community pharmacies who participated in the study and all participants who voluntarily agreed to complete the survey.

\section{Author Contributions}

All authors contributed to data analysis, drafting or revising the article, have agreed on the journal to which the article will be submitted, gave final approval of the version to be published, and agree to be accountable for all aspects of the work.

\section{Funding}

This study was funded by AstraZeneca, Portugal.

\section{Disclosure}

Dr. Correia-de-Sousa reports Advisory Board from Boehringer Ingelheim; personal fees and Advisory Board from GSK; grants, personal fees, and Advisory Board from AstraZeneca; personal fees and Advisory Board from Bial; non-financial support from Mundipharma; personal fees from Sanofi; Advisory Board from Novartis, outside the 
submitted work. The remaining authors declare no conflicts of interests.

\section{References}

1. The Global Asthma Report 2018 [Internet]. Auckland, New Zealand; 2018. Available from: www.globalasthmanetwork.org. Accessed April 6, 2021.

2. Bugalho de Almeida A, Todo-bom A, Fonseca $\mathrm{J}$ a, Morais de Almeida M, Loureiro C, Azevedo LF, et al. INASma - Sumário do Inquérito Nacional de Controlo da Asma. DGS; 2010. Available from: https://www.dgs.pt/documentos-e-publicacoes/sumario-doinquerito-nacional-de-controlo-da-asma-pdf.aspx.

3. de Sousa JC, Santo ME, Colaço T, Almada-Lobo F, Yaphe J. Asthma in an Urban Population in Portugal: a prevalence study. BMC Public Health. 2011;11(1):347. doi:10.1186/1471-2458-11-347

4. Sa-Sousa A, Morais-Almeida M, Azevedo LF, et al. Prevalence of asthma in Portugal - The Portuguese National Asthma Survey. Clin Transl Allergy. 2012;2(1):1-12. doi:10.1186/2045-7022-2-15

5. Cockcroft DW. Clinical Concerns With Inhaled $\beta 2$-Agonists Adult Asthma Introduction: Background. Clin Rev Allergy Immunol. 2006;31:197-208.

6. Suissa S, Blais L, Ernst P. Patterns of increasing $\beta$-agonist use and the risk of fatal or near-fatal asthma. Eur Respir J. 1994;7(9):1602-1609. doi:10.1183/09031936.94.07091602

7. Spitzer WO, Suissa S, Ernst P, et al. The use of beta-agonists and the risk of death and near death from asthma. N Engl J Med. 1992;327 (26): 1832-1835.

8. Patel M, Pilcher J, Reddel HK, Pritchard A, Corin A, Helm C, et al. Metrics of salbutamol use as predictors of future adverse outcomes in asthma. Clin Exp Allergy. 2013;43:1144-51.

9. Gerald JK, Carr TF, Wei CY, Holbrook JT, Gerald LB. Albuterol Overuse: A Marker of Psychological Distress? J Allergy Clin Immunol Pr. 2015;3(6):957-62.

10. Cabrera CS, Nan C, Lindarck N, Beekman MJHI, Arnetorp S, van der Valk RJP. Sabina: global programme to evaluate prescriptions and clinical outcomes related to short-acting $\beta 2$-agonist use in asthma. Eur Respir J. 2020;55(2).

11. Fonseca JA, Azevedo L. Validation of a questionnaire (CARAT10) to assess rhinitis and asthma in patients with asthma. Allergy. 2010;65:1042-8.

12. Global Initiative for Asthma (GINA). Pocket Guide for Asthma Management and Prevention; 2020.

13. Global Strategy for Asthma Management and Prevention [Internet]; 2019. Available from: www.ginasthma.org. Accessed April 6, 2021.

14. Bloom CI, Cabrera C, Arnetorp S, et al. Asthma-Related Health Outcomes Associated with Short-Acting $\beta 2$-Agonist Inhaler Use: an Observational UK Study as Part of the SABINA Global Program. Adv Ther. 2020;37(10):4190-4208. doi:10.1007/s12325-020-01444-5
15. Janson C, Menzies-Gow A, Nan C, et al. SABINA: an Overview of Short-Acting 32 -Agonist Use in Asthma in European Countries. $A d v$ Ther. 2020;37(3):1124-1135. doi:10.1007/s12325-020-01233-0

16. Nwaru BI, Ekström M, Hasvold P, Wiklund F, Telg G, Janson C. Overuse of short-acting $\beta$ 2-agonists in asthma is associated with increased risk of exacerbation and mortality: a nationwide cohort study of the global SABINA programme. Eur Respir J. 2020;55 (4):1901872. doi:10.1183/13993003.01872-2019

17. Thomson NC. Reliever Inhaler Overuse, Asthma Symptoms, and Depression. J Allergy Clin Immunol Pract. 2015;3(6):963-964. (). doi:10.1016/j.jaip.2015.07.002

18. Eisner MD, Lieu TA, Chi F, et al. Beta agonists, inhaled steroids, and the risk of intensive care unit admission for asthma. Eur Respir J. 2001;17(2):233LP- 240. doi:10.1183/09031936.01.17202330

19. Observatório Nacional das Doenças Respitratórias. Observatório Nacional das Doenças Respiratórias - Relatório 2017; 2017. [In Portuguese Language].

20. Direção-Geral DS. Monitorização e Tratamento Para o Controlo da Asma na Criança, no Adolescente e no Adulto. 006/2018 Portugal; 2018. 1-46. [In Portuguese Language].

21. Slejko JF, Ghushchyan VH, Sucher B, et al. Asthma control in the United States, 2008-2010: indicators of poor asthma control. $J$ Allergy Clin Immunol. 2014;133(6):1579-1587. doi:10.1016/j. jaci.2013.10.028

22. Francis MLL, Andrews R, Buckingham R, Evans H, Francis C, Houston R, et al. Why asthma still kills: the National Review of Asthma Deaths (NRAD) Confidential Enquiry report. Royal College of Physicians. London; 2014.

23. Worth A, Hammersley V, Knibb R, et al. Patient-reported outcome measures for asthma: a systematic review. Npj Prim Care Respir Med. 2014;24. doi:10.1038/npjpcrm.2014.20

24. Pavord ID, Mathieson N, Scowcroft A, Pedersini R, Isherwood G, Price D. The impact of poor asthma control among asthma patients treated with inhaled corticosteroids plus long-acting $\beta 2$-agonists in the United Kingdom: A cross-sectional analysis. npj Prim Care Respir Med. 2017;27(17).

25. Yaghoubi M, Adibi A, Safari A, Fitzgerald JM, Sadatsafavi M. The Projected Economic and Health Burden of Uncontrolled Asthma in the United States. Am J Respir Crit Care Med. 2019;200(9):1102-12.

26. Sá-Sousa A, Amaral R, Morais-Almeida M, et al. Asthma control in the Portuguese National Asthma Survey. Rev Port Pneumol. 2015;21 (4):209-213.

27. Chatterjee $\mathrm{AB}$. Reliability in reporting asthma history and age at asthma onset. J Asthma. 2015;51(9):956-63.

28. Hafferty JD, Campbell AI, Navrady LB, et al. Self-reported medication use validated through record linkage to national prescribing data. $J$ Clin Epidemiol. 2018;94:132-142. doi:10.1016/j.jclinepi.20 17.10.013.

\section{Publish your work in this journal}

The Journal of Asthma and Allergy is an international, peer-reviewed open-access journal publishing original research, reports, editorials and commentaries on the following topics: Asthma; Pulmonary physiology; Asthma related clinical health; Clinical immunology and the immunological basis of disease; Pharmacological interventions and new therapies. The manuscript management system is completely online and includes a very quick and fair peer-review system, which is all easy to use. Visit http://www.dovepress.com/testimonials.php to read real quotes from published authors. 